\title{
Inhaled powder compared with aerosol administration of fenoterol in asthmatic children
}

\author{
STEPHEN CHAMBERS, JANET DUNBAR, AND BRENT TAYLOR \\ Department of Paediatrics, Christchurch Clinical School of Medicine, Christchurch Hospital, New Zealand
}

SUMMARY Fenoterol as a powdered inhalation was shown to have a longer and stronger bronchodilator effect than the same dose inhaled from a standard metered dose aerosol in a double-blind doubleplacebo controlled cross-over study in 13 severely asthmatic children. The powder method of administration is free from many of the disadvantages of pressurised aerosols and may prove the method of choice in childhood.

The most widely used method of administering sympathomimetic drugs in adults is by way of a pressurised aerosol, but aerosols are not widely recommended by paediatricians. ${ }^{1-3}$ Aerosols have some disadvantages: despite careful tuition they are used ineffectively by $14 \%$ of adults ${ }^{4}$ and probably by an even greater proportion of children; they may be over-used especially in early adolescence, ${ }^{2}$ and the propellant chlorofluorocarbon is potentially harmful to both the patient and the environment. ${ }^{5-7}$

As an alternative, a powder inhaler can be used by nearly all adults. ${ }^{4}$ It is nonpolluting and doses can be more easily regulated. However, there is little information about the effectiveness of sympathomimetics administered in this form. In the present study the relief of bronchospasm by a standard dose of fenoterol from a pressurised aerosol was compared with that obtained by the same dose administered from a powder inhaler.

\section{Methods and patients}

13 children were studied ( 6 boys and 7 girls) aged 6 to 12 (mean 8.7) years. All were severe recurrent or chronic asthmatics (grade $\mathrm{C}$ or $\mathrm{D})^{2}$ under continuous intensive oral bronchodilator and prophylactic chemotherapy; the mean duration of symptoms was 6.7 years (range 6 months to 10 years).

No subject had had a sympathomimetic or theophylline preparation within 8 hours of study. Sodium cromoglycate (4 subjects), beclomethasone dipropionate (4 subjects), or both (3 subjects) were continued; these inhalations were taken at least 2 hours before the study on test mornings.

Respiratory function was assessed by peak expiratory flow rates (PEFR) with a Wright peak flow meter, the highest of 3 measurements on each occasion, before drug administration and thereafter at 15 and 30 minutes, and at 1, 2, 3, 4, and 5 hours. Actual PEFR values were converted to percentage of mean normal PEFR for height ${ }^{8}$ to allow intersubject comparison. The baseline variation during the study averaged $4.5 \%$ (maximum $17 \%$ ).

At the same time on 2 separate days the active drug $(200 \mu \mathrm{g}$ fenoterol, either one puff from a standard metered dose commercial aerosol or one capsule via an Italseber powder inhaler) together with the complementary placebo (propellant or glucose powder only) were given on a double-dummy randomised double-blind cross-over basis. Tuition and practice with placebo preparations was given before the trial.

\section{Results}

All patients completed the trial; each child showed improvement in PEFR after the inhalations on each test day. Both preparations were well tolerated and neither produced any side effect.

The results of the treatments are compared in the Figure. A two-way analysis of variance showed a significant difference in the mean percentage expected PEFR between the two treatments $(P<0.05)$ with the powder superior. The powder

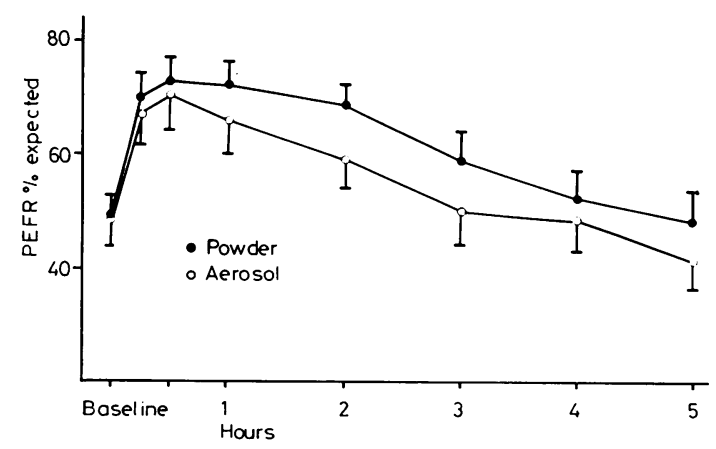

Figure Comparison of inhaled powder versus aerosol administration of $200 \mu \mathrm{g}$ fenoterol to 13 severely asthmatic children (mean $\pm S E$ ). 
treatment also provided longer bronchodilatation, shown by comparison of the times for PEFR to return towards baseline $(\mathrm{P}<0.05$ at $\mathrm{PEFR}$ baseline $+10 \%$; paired Student's $t$ ).

\section{Discussion}

This study suggests that fenoterol administered from a powder inhaler is more effective, providing both a longer and stronger bronchodilator effect, then when administered from a pressurised aerosol to asthmatic children. Presumably the powder is better inhaled.

In asthmatic adults who used aerosols well, studies with salbutamol showed no difference in efficacy between powder inhalation or aerosol..$^{9-10}$ However, those patients who used aerosols poorly did better with powder inhalations. ${ }^{9}$

Fine particles of the drug are contained in a base of fine glucose. This mixture can be inhaled at very low flow rates. There are no problems with inhaled sugar; lactose has been used with sodium cromoglycate for at least 12 years without side effects. The powder is dispensed in individual capsules which has the advantage in childhood that parents can monitor the number of capsules being used.

This study was supported in part by the Canterbury Medical Research Foundation, and Boehringer
Ingelheim provided the trial materials. We are grateful to D M Fergusson for statistical advice, and to Miss K Read for secretarial assistance.

\section{References}

1 Bierman C W, Pierson W E. Hand nebulizers and asthma therapy in children and adolescents. Pediatrics $1974 ; 54$ : 668-70.

2 Williams H E, Phelan P D. Asthma. In: Respiratory illness in children. Oxford: Blackwell, 1975.

3 Taylor B. Severe asthma in childhood. NZ Med J 1977; 85: 433-5.

4 Patterson I C, Crompton G K. Use of pressurised aerosols by asthmatic patients. Br Med J 1976; 1 : 76-7.

5 Editorial: Fluorocarbon aerosol propellants. Lancet $1975 ; 1$ : $1073-4$.

6 Editorial: Wet or dry inhalers? Lancet 1978; 1 : 79-80.

7 McLean A E M. Chlorofluorocarbons-in the can, in man, and in the atmosphere. Br J Clin Pharmacol 1977; 4:663-8.

8 Cogswell J J, Hull D, Milner A D, Norman A P, Taylor B. Lung function in childhood. III. Measurement of air flow resistance in healthy children. $\mathrm{Br} J$ Dis Chest 1975; 69: 177-87.

9 Duncan D, Paterson I C, Harris D, Crompton G K. Comparison of the bronchodilator effects of salbutamol inhaled as a dry powder and by conventional pressurised aerosol. BrJ Clin Pharmacol 1977; 4: 669-71.

10 Hetzel M R, Clark T J H. Comparison of salbutamol rotahaler with conventional pressurised aerosol. Clin Allergy 1977; 7 : 563-8.

Correspondence to Dr Brent Taylor, Department of Paediatrics, Christchurch Hospital, Christchurch, ! New Zealand. 